\title{
Development of missing data prediction model for carbon monoxide
}

\author{
Nurul Latiffah Abd Rani a, Azman Azid a, ${ }^{\text {, }}$, Muhamad Shirwan Abdullah Sani ${ }^{b}$, Mohd Saiful Samsudin ${ }^{\text {, }}$ \\ Ku Mohd Kalkausar Ku Yusof a, Siti Noor Syuhada Muhammad Amin c, Saiful Iskandar Khalit a \\ a Faculty Bioresources and Food Industry, Universiti Sultan Zainal Abidin (UniSZA), Besut Campus, 22200 Besut, Terengganu, Malaysia \\ b International Institute for Halal Research and Training, International Islamic University Malaysia, Selangor, Malaysia \\ c Faculty of Health Sciences, Universiti Sultan Zainal Abidin (UniSZA), Gong Badak Campus, 21300 Kuala Nerus, Terengganu, Malaysia \\ * Corresponding author: azmanazid@unisza.edu.my
}

\section{Article history}

Received 17 January 2018

Revised 22 March 2018

Accepted 20 May 2018

Published Online 4 February 2018

\begin{abstract}
Carbon monoxide $(\mathrm{CO})$ is one of the most important pollutants since it is selected for API calculation. Therefore, it is paramount to ensure that there is no missing data of $\mathrm{CO}$ during the analysis. There are numbers of occurrences that may contribute to the missing data problems such as inability of the instrument to record certain parameters. In view of this fact, a $\mathrm{CO}$ prediction model needs to be developed to address this problem. A dataset of meteorological and air pollutants value was obtained from the Air Quality Division, Department of Environment Malaysia (DOE). A total of 113112 datasets were used to develop the model using sensitivity analysis (SA) through artificial neural network (ANN). SA showed particulate matter $\left(\mathrm{PM}_{10}\right)$ and ozone $\left(\mathrm{O}_{3}\right)$ were the most significant input variables for missing data prediction model of $\mathrm{CO}$. Three hidden nodes were the optimum number to develop the ANN model with the value of $R^{2}$ equal to 0.5311 . Both models (artificial neural network-carbon monoxide-all parameters (ANN-CO-AP) and artificial neural network-carbon monoxide-leave out (ANN-CO-LO)) showed high value of $\mathrm{R}^{2}(0.7639$ and 0.5311$)$ and low value of RMSE (0.2482 and $0.3506)$, respectively. These values indicated that the models might only employ the most significant input variables to represent the $\mathrm{CO}$ rather than using all input variables.
\end{abstract}

Keywords: Prediction model, carbon monoxide, Malaysia, sensitivity analysis, missing data model

\section{INTRODUCTION}

Air pollution imposes severe environmental challenges as well as prominent health risks to human (Najafpoor et al., 2014). The worst air pollution problem usually takes place at urban areas of both developed and developing countries (Hassanzadeh et al., 2009) which indirectly affects the quality of life as well as public health. Air pollutions are mostly produced by natural activities such as volcano eruptions and human activities, owing to the industrial processes, production of energy from power plants, residential heating and open burning (Najafpoor et al., 2014; Afroz et al., 2003). In addition, the fuel burning vehicles in urban area have worsened the air quality (Wang \& Lu, 2006). Consequently, the human health and environment may be affected by the air pollution and in the long term, air pollution has a tendency to intensify the threats to earth.

Incomplete combustion of hydrocarbons contributes to the presence of carbon monoxide (CO) (Levy, 2015), which associated to cardiovascular diseases, daily mortality and morbidity (Chen et al., 2011). In a homogeneous environment, air pollutant levels including $\mathrm{CO}$ at each fixed monitoring stations are indicated by the applied measurements. Nevertheless, the dispersion of the actual pollutant contents is still unknown, owing to substantial influences of the prevailing conditions of dispersion, emission sources distribution and the region topography (Zoroufchi \& Fatehifar, 2015) and thus, affecting the exact concentrations of the measured air pollutants.

Besides $\mathrm{PM}_{10}$, the development of $\mathrm{CO}$ missing data prediction model is important due to the fact that this pollutant is one of the leading contributors to the air pollutants and produced from most of the sites (Azid et al., 2016 \& Mohamad et al., 2015). According to Awang et al., (2015) $\mathrm{PM}_{10}$ and $\mathrm{CO}$ are being grouped into the same component, indicating that $\mathrm{CO}$ is as important as $\mathrm{PM}_{10}$ and may come from the same sources since it is being grouped together with $\mathrm{PM}_{10}$.

Missing data is a common occurrence in air pollution studies. Failure of equipment and anomalous measurement are the reasons for this missing data (Chen et al., 2016). Researchers are opted to remove the missing data prior to statistical analysis. However, this action can reduce the data size. The data becomes unrepresentative with the removal of massive missing data and subsequently, unreliable result will be produced. Hence, imputing the missing values can be the alternative way to evade unreliable or ravage result on the statistical interpretation.

In general, single and multiple imputation methods are the acceptable approaches to generate complete information matrices (Little \& Rubin, 1987). One value for each missing one is specifically filled in the former method. For the multiple-imputation, simulated values for each missing data are generated to appropriately determine the uncertainty of the missing data (Junninen et al., 2004) using expectation maximization based (EMB) algorithm. Other algorithms are also applicable; however, EMB algorithm possesses unique features such as simplicity, power, rapidity (Honaker et al., 2011) and practicality in forecasting the missing air quality data using ANN model.

ANN is a non-linear model (Kukkonen et al., 2003) and has been acknowledged as a cost-effective model (Azid et al., 2014) since it is able to discover and ascertain patterns (Zare, 2014), solve complex functions and produce reliable air pollutants prediction. This model can be utilized to assist forthcoming planning with the presence of missing data during the air monitoring, mend air quality management system (Kumar \& Goyal, 2011). Besides air quality, ANN model has also been applied for the water quality studies. (Zali et al., 2011) used ANN for 
the water quality index (WQI) prediction for Kinta River, Malaysia. Besides that, (Nasir et al., 2011) also applied ANN in their study for WQI prediction model in Juru River, Malaysia.

\section{EXPERIMENTAL}

\section{Study area}

There are 52 continuous monitoring stations (N06 $25.424^{\prime}$ E $100^{\circ}$ $20.880^{\prime}$ to ${\mathrm{N} 04^{\circ}}^{\circ} 15.016^{\prime} \mathrm{E} 117^{\circ} 56.166^{\prime}$ ) for ambient air quality throughout Malaysia (Fig. 1). These stations were chosen due to the desired locations in urban, suburban, and industrial area (Azid et al., 2015).

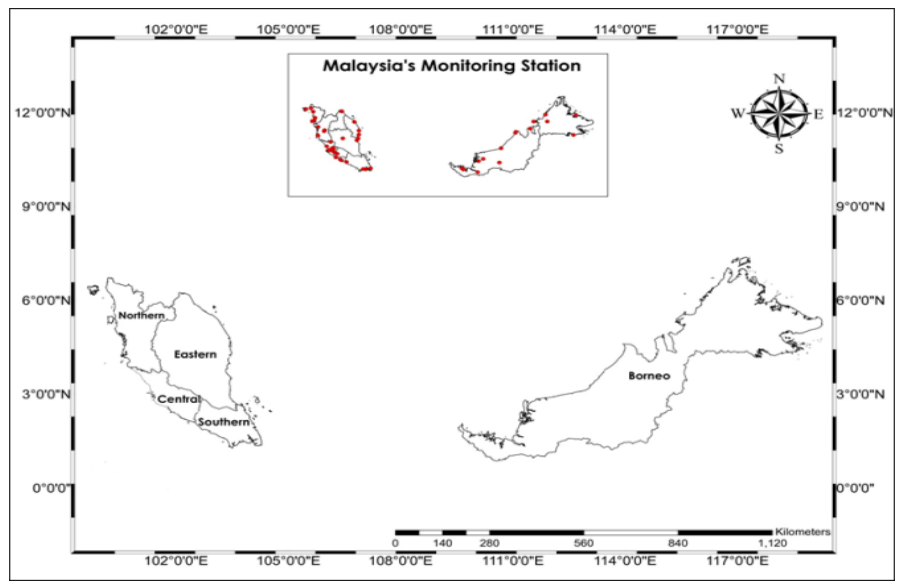

Source: (Kanniah et al., 2016; DOE, 2004)

Fig. 1 Continuous ambient air quality monitoring stations in Malaysia

\section{Data collection}

The air pollutants and meteorological data were obtained from the Air Quality Division, Department of Environment (DOE) Malaysia. The obtained data in this study was entailed daily average observations for most of air pollutants $\left(\mathrm{PM}_{10}, \mathrm{NO}_{2}, \mathrm{CO}, \mathrm{O}_{3}, \mathrm{NO}, \mathrm{NO}_{x}, \mathrm{THC}, \mathrm{CH}_{4}\right.$, $\mathrm{NmHC}, \mathrm{SO}_{2}$ ) and meteorological conditions (wind direction, wind speed, temperature, humidity, UVB) from 2010 until 2015. These variables were independently analysed at each monitoring stations. The model equipments for continuously monitoring program (CAQM) on each atmospheric pollutants and meteorological parameters were listed in Table 1

\section{Variables selection}

The best input variables for the $\mathrm{CO}$ missing data modelling were selected prior to the designing of the model. Input nodes in ANN were based on the selected input variables, which significantly contributing to the process of forecasting. In addition, high numbers of input could cause reduction of training speed, over-fitting, redundancy and noise variables (Ababneh et al., 2014). Thus, only selected input variables were used for ANN analysis.

One of the methods to select the best input variables for the prediction of CO missing data modelling using ANN model was by applying sensitivity analysis (SA). This method used "leave-one-out" technique to rank the importances of the model input variables by considering their influences on the unpredictability of the model output (Manache \& Melching, 2008). This method was carried out manually whereby one-by-one parameters were removed. The $\mathrm{R}^{2}$ values of each leave one out parameters were applied to show the differences of $\mathrm{R}^{2}$ The percentage $(\%)$ contribution of the parameters was determined by applying Equation 1:

$$
\% \text { contribution }=\left(\frac{b_{i}-a_{i}}{z_{i}}\right) 100
$$

where:

$\mathrm{ai}=$ the value of $\mathrm{R}^{2}$ after a leave-one-out parameter for each model

$\mathrm{bi}=$ the reference value of $\mathrm{R}^{2}$ from ANN-CO-AP

$\mathrm{zi}=$ the sum value of difference $\mathrm{R}^{2}$
SA has been used in various fields of environmental studies. For instance, it has been used by (Latif et al., 2014) in their study to investigate the important level of each inputs $\left(\mathrm{CO}, \mathrm{NO}, \mathrm{NO}_{2}, \mathrm{NO}_{\mathrm{x}}, \mathrm{O}_{3}\right.$, $\mathrm{PM}_{10}, \mathrm{SO}_{2}, \mathrm{THC}, \mathrm{CH}_{4}$ and $\mathrm{NmHC}$ ) on the output (vehicles). Meanwhile, (Asadollahfardi et al., 2016) applied SA to determine which of the input variables have a great role in predicting ground layer of $\mathrm{O}_{3}$ where in their study, the maximum and minimum roles for ground-level $\mathrm{O}_{3}$ concentration prediction are $\mathrm{PM}_{2.5}$ and benzene, respectively. On top of that, research done by (Rahimi, 2017) also applied $\mathrm{SA}$ in prediction of $\mathrm{NO}_{2}$ and $\mathrm{NOx}$ by calculating important level of input variables in prediction.

Table 1 The CAQM model equipment for each parameter.

\begin{tabular}{|c|c|}
\hline Parameter & Model equipment \\
\hline Particulate Matter $\left(\mathrm{PM}_{10}\right), \mu \mathrm{g} / \mathrm{m}^{3}$ & BAM-1020 Beta Attenuation \\
\hline Wind Speed (WS), km/hr & Met One 010C \\
\hline Wind Direction (WD), ${ }^{\circ}$ & Met One 010C \\
\hline Air Temperature (AT), ${ }^{\circ} \mathrm{C}$ & Met One 062 \\
\hline Relative Humidity (RH), \% & Met One 083D \\
\hline Oxides of Nitrogen (NOx), ppm & Teledyne API Model 200A/200E \\
\hline Nitrogen Monoxide (NO), ppm & Teledyne API Model 200A/200E \\
\hline \multicolumn{2}{|l|}{ Ultraviolet-b $\left(U V_{b}\right), J / m^{2} h r$} \\
\hline Methane $\left(\mathrm{CH}_{4}\right), \mathrm{ppm}$ & Teledyne API M4020 \\
\hline $\begin{array}{l}\text { Non-methane Hydrocarbon } \\
(\mathrm{NmHC}), \mathrm{ppm}\end{array}$ & Teledyne API M4020 \\
\hline Total Hydrocarbon (THC), ppm & Teledyne API M4020 \\
\hline Sulphur Dioxide $\left(\mathrm{SO}_{2}\right), \mathrm{ppm}$ & Teledyne API Model 100A/100E \\
\hline Nitrogen Dioxide $\left(\mathrm{NO}_{2}\right)$, ppm & Teledyne API Model 200A/200E \\
\hline Ozone $\left(\mathrm{O}_{3}\right), \mathrm{ppm}$ & Teledyne API Model 400/400E \\
\hline Carbon Monoxide (CO), ppm & Teledyne API Model 300/300E \\
\hline
\end{tabular}

\section{Data pre-processing}

Analysis, filtration and transformation were implemented to organize the obtained data set for the model development. There were a few missing data and outliers observed which might be resulted due to technical failure (Zakaria \& Noor, 2018) and incorrect recorded results during the data collections. The outliers should not be deleted because they might give true measurements (Burke, 1999). Moreover, in air pollution modelling, it was important to use $\widetilde{w}$ whole year data by considering the full coverage variation of the seasonal pollutant levels and meteorological parameters (Arhami et al., 2013).

In this study, the missing data was replaced by using the EMB (expectation-maximization with bootstrapping) algorithm. Likelihood observed data was represented as shown in Equation 2:

$$
p\left(D^{o b s}, M \mid \theta\right)=p\left(M \mid D^{o b s}\right) p\left(D^{o b s} \mid \theta\right)
$$

With $\mathrm{D}^{\text {obs }}$ and $\mathrm{M}$ were known as observed data and missingness matrix, respectively. While, likelihood was written as Equation 3 if only complete data parameters were concerned:

$$
L=\left(\theta \mid D^{o b s}\right) \propto p\left(D^{o b s} \mid \theta\right)
$$

While, equation could be rewrite as Equation 4 based on the iterated expectations law: 


$$
p\left(D^{o b s} \mid \theta\right)=\int p(D \mid \theta) d D^{m i s}
$$

The posterior with this likelihood and a flat prior on $\theta$ as shown in Equation 5:

$$
p\left(\theta \mid D^{o b s}\right) \propto p\left(D^{o b s} \mid \theta\right)=\int p(D \mid \theta) d D^{m i s}
$$

Table 2 illustrates the statistical measurements for selected meteorological and air pollutant variables (after SA) for the modelling of CO missing data using ANN.

Table 2 Descriptive information for selected variables for modelling of CO missing data.

\begin{tabular}{cccc}
\hline Variables & Min & Max & Mean \\
\hline $\mathrm{O}_{3}(\mathrm{ppm})$ & 0 & 0.2 & 0.03 \\
$\mathrm{PM}_{10}\left(\boldsymbol{\mu g} / \mathrm{m}^{3}\right)$ & 0 & 763 & 49.68 \\
\hline
\end{tabular}

The best input variables were used in prediction, evaluation and validation processes of the ANN technique. However, prior to these processes, the data variables were normalized by employing scaling range of $(-1,1)$ to increase training speed, minimize variable values differences and reduce computational problems (Srinivasan et al., 1994). The hyperbolic tangent function was used to transform value to be between -1 and 1 , for normalization (JMP, 2012) with the formula of the hyperbolic tangent function as shown in equation 6 :

$$
\text { Hyperbolic tangent function }=\frac{e^{2 x}-1}{e^{2 x}+1}
$$

In addition, data normalization within range output of activation function of ANN output layer was necessary when using non-linear activation function (Zhang et al., 1998). Studies revealed that only small errors of prediction were produced when applying the hyperbolic tangent function as compared to the sigmoid (logistic) transfer function (Chaloulakou et al., 2003).

It was crucial to select the optimum number of nodes in hidden layer since high number of nodes might result in overfitting (He et al., 2014) while less number of nodes might not adequately capture the information. The proposed equation was to determine the appropriate number of nodes ranges (Fletcher \& Goss, 1993) as shown Equation 7:

$$
\text { Number of nodes ranges }=2 S^{\frac{1}{2}}-0 \text { to } 2 S-1
$$

where, $\mathrm{S}$ is the number of input nodes and $\mathrm{O}$ is the number of output nodes.

\section{Prediction, evaluation and validation of ANN model}

The system predicted missing data of $\mathrm{CO}$ with the input selection used in ANN was based on the results of SA. To determine the error in predicting the concentration of $\mathrm{CO}$ and models performance evaluation, a Root Mean Squared Error (RMSE) which indicated in Equation 8 was applied:

$$
\operatorname{RMSE}=\sqrt{\frac{1}{n} \sum_{t=1}^{n}\left(0_{t}-P_{t}\right)^{2}}
$$

Meanwhile, model validity was illustrated by applying coefficient of determination $\left(\mathrm{R}^{2}\right)$ between observations and predicted as shown in Equation 9:

$$
\mathbf{R}^{2}=1-\left(\sum_{\mathrm{t}=1}^{\mathrm{n}} \frac{\left(\mathbf{0}_{\mathrm{t}}-\mathbf{P}_{\mathrm{t}}\right)^{2}}{\left(\mathbf{0}_{\mathrm{t}}-\overline{\mathrm{o}}\right)^{2}}\right)
$$

where, $\mathbf{0}_{\mathbf{t}}, \mathbf{P}_{\mathbf{t}}$ and $\bar{o}$ represent observed value, predicted value and observed mean value of $\mathrm{CO}$ concentrations at time, $t$ respectively, a $n$ is the number of data (Ahmat et al., 2015).

\section{RESULTS AND DISCUSSION}

Table 3 shows the SA results for the prediction of CO. From the result, different values $\mathrm{R}^{2}$ exhibited different parameter values that affected the prediction of $\mathrm{CO}$. The $\%$ contribution $>10 \%$ indicated strong contribution towards the CO presence (Azid et al., 2016). The highest and lowest influences of input variable were $\mathrm{PM}_{10}$ and WD with $\%$ contribution of $35.95 \%$ and $0.92 \%$, respectively.

Based on the $\mathrm{R}^{2}$ and $\%$ contribution in Table 3 , the most important input variables were ranked as $\mathrm{PM}_{10}>\mathrm{O}_{3}>\mathrm{NO}_{2}>\mathrm{SO}_{2}>\mathrm{NO}_{\mathrm{x}}>\mathrm{CH}_{4}>\mathrm{Temp}$ $>\mathrm{NO}>$ Humidity $>\mathrm{THC}>\mathrm{WS}>\mathrm{UVB}>\mathrm{NmHC}>\mathrm{WD}$ with $\mathrm{PM}_{10}$ and $\mathrm{O}_{3}$ became the main contributors to the $\mathrm{CO}$ presence in this study.

Studies on SA shown that air pollutants rendered a strong influence on the climate daily variability (Ababneh et al., 2014). This finding was supported by SA study on the air pollution index (API) which was found that $\mathrm{PM}_{10}$ and $\mathrm{CO}$ were the main contributors to the air pollutants (Azid et al., 2016). In the Southeast Asia including Malaysia, these pollutants have been acknowledged as significant atmospheric pollutants in major cities and were produced by complete combustion of motor vehicles as well as various industrial practices (Latif et al., 2011; Mustafa et al., 2012). Beside of $\mathrm{PM}_{10}, \mathrm{O}_{3}$ was also correlated to

\begin{tabular}{|c|c|c|c|}
\hline Model & $\mathbf{R}^{2}$ & Difference, $\mathbf{R}^{2}$ & $\%$ Contributior \\
\hline ANN-CO-AP & 0.7639 & & \\
\hline ANN-LPM 10 & 0.6618 & 0.1021 & 35.95 \\
\hline $\mathrm{ANN}-\mathrm{LO}_{3}$ & 0.6784 & 0.0855 & 30.11 \\
\hline ANN-LNO ${ }_{2}$ & 0.7511 & 0.0128 & 4.50 \\
\hline ANN-LSO ${ }_{2}$ & 0.7515 & 0.0124 & 4.36 \\
\hline ANN-LNO & 0.7519 & 0.0120 & 4.21 \\
\hline ANN-LCH ${ }_{4}$ & 0.7542 & 0.0097 & 3.41 \\
\hline ANN-LTEMP & 0.7543 & 0.0096 & 3.37 \\
\hline ANN-LNO & 0.7544 & 0.0095 & 3.35 \\
\hline ANN-RH & 0.7545 & 0.0094 & 3.30 \\
\hline ANN-LTHC & 0.7577 & 0.0061 & 2.17 \\
\hline ANN--LWS & 0.7584 & 0.0054 & 1.92 \\
\hline ANN-LUVB & 0.7601 & 0.0038 & 1.33 \\
\hline ANN-LNMHC & 0.7607 & 0.0031 & 1.11 \\
\hline ANN-LWD & 0.7613 & 0.0026 & 0.92 \\
\hline Total & & 0.2839 & 100.00 \\
\hline
\end{tabular}
CO since the letter was originated from diesel fuel (Rani et al., 2017) and mobile sources, causing it to become secondary contributor to ozone depletion (Kumar et al., 2017).

Table 3 Sensitivity analysis for selected input variables for CO predicted model.

Table 4 shows the $\mathrm{R}^{2}$ and RMSE values for ANN with a hidden layer and different number of hidden nodes. Based on two main input variables obtained from SA, the most appropriate number of hidden nodes was between 1 to 3 . Among these hidden nodes, three hidden nodes exhibited the highest $\mathrm{R}^{2}$ and the lowest RMSE. Higher value of $\mathrm{R}^{2}$ indicated a closer relation between predicted output value and the exact output value. Moreover, the three hidden nodes have lower RMSE value compared to other hidden nodes where the nearest RMSE value to 0 was indicated to the best ANN model performance (Ababneh et al., 2014). Thus, three hidden nodes were considered as the optimum number for the ANN model. 
Post ANN-model prediction step, model evaluation and validation were carried out to evaluate the ability of ANN in the prediction process. In Table 5, ANN-CO-AP (14 variables) and ANN-CO-LO (using $\mathrm{PM}_{10}$ and $\mathrm{O}_{3}$ ) prediction models showed RMSE (0.2482 and $0.3506)$ and $R^{2}(0.7639$ and 0.5311$)$ respectively. The nearest RMSE value to 0 and $\mathrm{R} 2$ to 1 were indicated to the best ANN model performance and model robustness (Zali et al., 2011), as well as provided the highest accuracy between predicted and actual output values (Ababneh et al., 2014). ANN-CO-LO was considered as the optimum model as it used fewer input variables $\left(\mathrm{PM}_{10}\right.$ and $\left.\mathrm{O}_{3}\right)$ although the model exhibited lower $\mathrm{R}^{2}(0.5311)$ and higher RMSE (0.3506). Moreover, more input data would lead to better predictions (Esfandani \& Nematzadeh, 2016). Thus, by reducing the input variables, $\mathrm{R}^{2}$ value would become lower.

Table 4 The coefficient of determination $\left(R^{2}\right)$ and error value (RMSE) for the ANN with a hidden layer and different number of hidden nodes.

\begin{tabular}{ccc}
\hline $\begin{array}{c}\text { No. of hidden } \\
\text { nodes }\end{array}$ & $\mathbf{R}^{2}$ & RMSE \\
\hline 1 & 0.4188227 & 0.3893862 \\
2 & 0.5257966 & 0.3546468 \\
3 & 0.5311124 & 0.3506089 \\
\hline
\end{tabular}

Table 5 Model evaluation and model validation for the different $\mathrm{CO}$ prediction models

\begin{tabular}{cccc}
\hline \multirow{2}{*}{ Models } & $\begin{array}{c}\text { Model } \\
\text { evaluation }\end{array}$ & $\begin{array}{c}\text { Model } \\
\text { validation }\end{array}$ \\
\cline { 3 - 4 } & RMSE & $\mathbf{R}^{2}$ \\
\hline 1 & $\begin{array}{c}\text { ANN-CO- } \\
\text { AP }^{1}\end{array}$ & 0.2482 & 0.7639 \\
2 & $\begin{array}{c}\text { ANN-CO- } \\
\text { LO }^{2}\end{array}$ & 0.3506 & 0.5311 \\
\hline
\end{tabular}

${ }^{1}$ All input variables were employed in ANN model.

${ }^{2} \mathrm{PM}_{10}$ and $\mathrm{O}_{3}$ input variables were employed in $\mathrm{ANN}$ model.

From the developed model, the ANN-CO-LO model equation could be interpreted as in Equation 10:

Predicted $\mathrm{CO}=-0.23+(-1.85 \times \mathrm{H} 1)+(-0.43 \times \mathrm{H} 2)+(9.19 \times \mathrm{H} 3)(10)$

Where;

$\mathrm{H} 1=\tanh [0.5 \times((-116.80 \times 03)+(0.0075 \times \mathrm{PM} 10)-0.86)]$

$\mathrm{H} 2=\tanh [0.5 \times((202.84 \times 03)+(-0.026 \times \mathrm{PM} 10)-1.81)]$

$\mathrm{H} 3=\tanh [0.5 \times((0.70 \times 03)+(0.0016 \times \mathrm{PM} 10)-0.19)]$

Based on this formula, the predicting $\mathrm{CO}$ missing data could be evaluated and validated efficiently.

\section{CONCLUSION}

In conclusion, only selected input variables were used to generate a model for missing CO data. By using SA, the number of input variables could be reduced based on their significant values to the presence of $\mathrm{CO}$. In this study, the most significant input variables were $\mathrm{PM}_{10}$ and $\mathrm{O}_{3}$. In addition to the selection of input variables, the selection number of hidden nodes was also vital to ensure the obtained results were not over fitting and only captured sufficient information. The optimum number of hidden nodes for this study was three, which exhibited had the highest $R^{2}(0.5311)$ and the lowest RMSE (0.3506) values as compared to other hidden nodes. Research done by Esfandani \& Nematzadeh (2016) showed that greater input number would give better prediction. Thus, by decreasing the input number by using less number of input variables, ANN-CO-LO model (used input variables $\mathrm{PM}_{10}$ and $\mathrm{O}_{3}$ ) gave lower $\mathrm{R}^{2}$ value compared to ANN-CO-AP which used all input variables (14 parameters). Although ANN-CO-LO model gave lower $\mathrm{R}^{2}$ value compared to ANN-CO-AP $\mathrm{R}^{2}$ value, ANN-CO-LO model still possessed better performance with good $R^{2}$ value $\left(R^{2}=\right.$ 0.5311). On top of that, the reductions-of air quality parameters was much applicable for air resource management because of its time and cost of operation. Hence, the ANN-CO-LO model could be utilized in predicting missing $\mathrm{CO}$ data.

\section{ACKNOWLEDGEMENT}

This manuscript has been funded through University Research Fund (Grant no.: UniSZA/2016/DPU/01) and Research Initiative Grant (RIGS16-363-0527) of International Islamic University Malaysia, Gombak, Selangor, Malaysia.

\section{REFERENCES}

Ababneh, M. F., Al-Manaseer, A. O., Btoush, M. H. 2014. PM $_{10}$ forecasting using soft computing techniques research. Journal of Applied Sciences, Engineering and Technology, 7(16): 3253-3265.

Afroz, R., Hassan, M. N., Ibrahim., N. A. 2003. Review of air pollution and health impacts in Malaysia. Environmental Research, 92(2): 71-77.

Ahmat, H., Yahaya, A. S., Ramli, N. A, 2016. The Malaysia PM $_{10}$ analysis using extreme value. Journal of Engineering Science and Technology,10(12): 1560 -1574 .

Arhami, M., Kamali, N., Rajabi, M. M. 2013. Predicting hourly air pollutant levels using artificial neural networks coupled with uncertainty analysis by Monte Carlo simulations. Environmental Science and Pollution Research, 20: 4777-4789.

Asadollahfardi, G., Tayebi, J. M., Mehdinejad, M., Rajabipour, M. J. 2016. Short-term prediction of atmospheric concentrations of ground-level ozone in Karaj using artificial neural network. Pollution, 2(4): 475-488.

Awang, N. R., Ramli, N. A., Yahaya, A. S., Elbayoumi, M 2015. Multivariate methods to predict ground level ozone during daytime, nighttime, and critical conversion time in urban areas. Atmospheric Pollution Research, 6:726-734.

Azid, A., Juahir, H., Ezani, E., Toriman, M. E., Endut, A., Rahman, M. N. A., Yunus, K., Kamarudin, M. K. A., Hasnam, C. N. C., Saudi, A. S. M., Umar, R. 2015. Identification source of variation on regional impact of air quality pattern using chemometrics Aerosol and Air Quality Research, 15: 15451558 .

Azid, A., Juahir, H., Toriman, M. K., Endut, A., Rahman, M. N. A., Kamarudin, M. K. A., Latif, M. T., Saudi, A. S. M., Hasnam, C. N. C., Yunus, K. 2016. Selection of the most significant variables of air pollutants using sensitivity analysis. Journal of Testing and Evaluation, 44(1): 376-384.

Azid, A., Juahir, H., Toriman, M., Kamarudin, M., Saudi, A., Hasnam, C. 2014 Prediction of the level of air pollution using principal component analysis and artificial neural network techniques: a case study in Malaysia. Water, Air, \& Soil Pollution, 225(8): 1-14.

Burke, S. 1999. Missing values, outliers, robust statistics and non-parametric methods. $L C^{*} G C$ Europe Online Suplement, 19-24.

Chaloulakou, A., Grivas, G., Spyrellis, N. 2003. Neural network and multiple regression models for $\mathrm{PM}_{10}$ prediction in athens: A comparative assessment, Journal of the Air \& Waste Management Association, 53(10): 1183-1190.

Chen, R.Pan, G., Zhang, Y., Xu, Q., Zeng, G., Xu, X. 2011. Ambient carbon monoxide and daily mortality in three Chinese cities: the China air pollution and health effects study (CAPES). Science of the Total Environment, 409(23): 4923-4928.

Chen, W., Tang, H., Zhao, H. 2016. Urban air quality evaluations under two versions of the national ambient air quality standards of China Atmospheric Pollution Research 7: 49-57.

DOE, Department Of Environment Malaysia. 2004. Malaysian Environmental Quality Report.

Esfandani, M. A., Nematzadeh, H. 2016. Predicting air pollution in Tehran: Genetic algorithm and back propagation neural network. Journal of AI and Data Mining, 4(1): 49-54.

Fletcher, D., Goss, E. 1993.Forecasting with neural networks: An application using bankruptcy data. Information and Management, 24:159-167.

Hassanzadeh, S., Hosseinibalam, F. Alizadeh, 2009. R. Statistical models and time series forecasting of sulfur dioxide: A case study Tehran. Environmental Monitoring and Assessment, 155(1): 149-155.

He, H., Lu, W. Z., Xue, Y. 2014.Prediction of particulate matter at street level using artificial neural networks coupling with chaotic particle swarm optimization algorithm. Building and Environment, 78: 111-117.

Honaker, J., King, G., Blackwell, M. 2011. Amelia II: A Program for Missing Data. Journal of Statistical Software, 45(7): 1-47. 
Junninen, H., Niska, H., Tuppurainen, K., Ruuskanen, J., Kolehmainen, M. 2004. Methods for imputation of missing values in air quality data sets. Atmospheric Environment, 38: 2895-2907.

Kanniah, K. D., Kaskaoutis, D. G., Lim, H. S., Latif, M. T., Zaman, N. A. F. K., Liew, J. 2016. Overview of atmospheric aerosol studies in Malaysia: Known and unknown. Atmospheric Research, 182: 302-318.

Kukkonen, J., Partanen, L., Karppinen, A., Ruuskanen, J., Junninen, H. Kolehmainen, M., Niska, H., Dorling, S., Chatterton, T., Foxall, R., Cawley, G. 2003. Extensive evaluation of neural network models for the prediction of $\mathrm{NO}_{2}$ and $\mathrm{PM}_{10}$ concentrations, compared with a deterministic modelling system and measurements in centralHel sinki. Atmospheric Environment 37: 4539-4550.

Kumar, A., Goyal, P. 2011. Forecasting of daily air quality index in Delhi. Science of the Total Environment, 409(24): 5517-5523.

Kumar, N., Middey, A., Rao, P. S. 2017. Prediction and examination of seasonal variation of ozone with meteorological parameter through artificial neural network at NEERI, Nagpur, India Urban Climate, 20: 148-167.

Latif, M. T., Azmi, S. Z., Noor, A. D. M., Ismail, A. S., Johny, Z., Idrus, S., Mohamad, A. F., And Mokhtar, M., 2011. The impact of urban growth on regional air quality surrounding the Langat River Basin, Malaysia, Environmentalist, 31(3): 315-324.

Latif, M. T., Dominick, D., Ahamad, F., Khan, M. F., Juneng, L., Hamzah, F. M., Nadzir, M. S. M. 2014. Long term assessment of air quality from a background station on the Malaysian Peninsula. Science of the Total Environment, 482-483: 336-348.

Levy, R. J. 2015. Carbon monoxide pollution and neurodevelopment: A public health concern. Neurotoxicology and Teratology, 49: 31-40.

Little, R. J. A., Rubin, D. B. 1987. Statistical Analysis with Missing Data, New York: Wiley.

Manache, G., Melching, C. S., 2008. Identification of reliable regression- and correlation-based sensitivity measures for importance ranking of water quality model parameters. Environmental Modelling \& Software, 23(5): 549 562.

Mohamad, N. D., Ash'aari, Z. H., Othman, M., 2015. Preliminary assessment of air pollutant sources identification at selected monitoring stations in Klang Valley, Malaysia. Procedia Environmental Sciences, 30: 121 - 126.

Mustafa, M., Syed Abdul Kader, S. Z., Sufian, A., 2012. Coping with climate change through air pollution control: Some legal initiatives from Malaysia 2012 International Conference on Environment, Energy and Biotechnology, Kuala Lumpur, Malaysia. May 5-6, 33,101-105.

Najafpoor, A., Hosseinzadeh, A., Allahyari, S., Javid, A., Esmaily, H. 2014 Modeling of $\mathrm{CO}$ and $\mathrm{NO}_{\mathrm{x}}$ produced by vehicles in Mashhad, 2012. Environmental Health Engineering And Management Journal, 1(1): 45-49.

Nasir, M. F. M., Juahir, H., Roslan, N., Mohd, I., Shafie, N. A., Ramli, N. 2011. Artificial neural networks combined with sensitivity analysis as a prediction model for water quality index in Juru River, Malaysia. International Journal of Environmental Protection, 1(3): 1-8.

Rahimi, A. 2017. Short-term prediction of $\mathrm{NO}_{2}$ and $\mathrm{NO}_{\mathrm{x}}$ concentrations using multilayer perceptron neural network: A case study of Tabriz, Iran Ecological Processes, 6:4.

Rani, N. L. A., Azid, A., Khalit, S. I., Gasim, M. B., Juahir, H, 2017. Selected Malaysia air quality pollutants assessment using chemometrics techniques. Journal of Fundamental and Applied Sciences, 9(2): 335-351.

Srinivasan, D., Liew, A.C., Chang, C. S. 1994. A neural network short-term load forecaster. Electric Power Systems Research, 28: 227-234.

Wang, X. K., Lu, W. Z. 2006. Seasonal variation of air pollution index: Hong Kong case study. Chemosphere 63(8): 1261-1272.

Zakaria, N. A., Noor, N. M. 2018.Imputation methods for filling missing data in urban air pollution data for Malaysia. Urbanism Arhitectură. Construcţii, 9(2): 159-166.

Zali, M. A., Retnam, A., Juahir, H., Zain, S. M., Kasim, M. F., Abdullah, B., Saadudin, S. B. 2011. Sensitivity analysis for water quality index (WQI) prediction for Kinta River. Malaysia World Applied Sciences Journal, 14 (Exploring Pathways to Sustainable Living in Malaysia: Solving the Current Environmental Issues): 60-65.

Zare, A. H. 2014. Evaluation of multivariate linear regression and artificial neural networks in prediction of water quality parameters. Journal of Environmental Health Science and Engineering, 12: 40.

Zhang, G., Patuwo, E. B., Hu, M. Y. 1998. Forecasting with artificial neural networks: The state of the Art. International Journal of Forecasting, 14: 3562.

Zoroufchi, B. K, Fatehifar, E. 2015. Optimal design of air quality monitoring network around an oil refinery plant: A holistic approach. International Journal of Environmental Science and Technology, 12(4): 1331-1342. 